\title{
The simple analytics of the environmental Kuznets curve
}

\author{
James Andreoni ${ }^{\mathrm{a}}$, Arik Levinson ${ }^{\mathrm{b}, *}$ \\ ${ }^{a}$ University of Wisconsin, Madison, Economics Department, Madison, WI 53706, USA \\ ${ }^{\mathrm{b}}$ Georgetown University, Economics Department, Washington, DC 20057, USA
}

Received 1 July 1999; accepted 1 February 2000

\begin{abstract}
Evidence suggests that some pollutants follow an inverse-U-shaped pattern relative to countries' incomes, a relationship that has been called an 'environmental Kuznets curve'. We present a simple and straight-forward static model of the microfoundations of this relationship, in which the curve depends on increasing returns in the technological link between consumption of a desired good and abatement of its undesirable byproduct. The curve does not depend on the dynamics of growth, political institutions, or even externalities, and can be consistent with market failure or efficiency. We conclude by presenting empirical support for increasing returns to abating some common air pollutants. (C) 2001 Elsevier Science B.V. All rights reserved.
\end{abstract}

Keywords: Environmental Kuznets curve; Economic growth; Pollution

JEL classification: Q2; D62; H23

\section{Introduction}

Evidence suggests that some pollutants follow an inverse-U-shaped pattern relative to countries' incomes. ${ }^{1}$ Due to its similarity to the time-series pattern of

*Corresponding author. Tel.: +1-202-687-5571; fax: +1-202-687-6102.

E-mail address: am16@georgetown.edu (A. Levinson).

${ }^{1}$ See, for example, Grossman and Krueger (1995); Holtz-Eakin and Selden (1995); Selden and Song (1994); Shafik and Bandyopadhyay (1992); World Bank (1992); Hilton and Levinson (1998); Kahn (1998); Chaudhuri and Pfaff (1998a); Galeotti and Lanza (1999); and Millimet and Stengos (1999), as well as recent special issues of Ecological Economics and Environment and Development Economics. 
income inequality described by Kuznets (1955), the environmental pattern has been called an 'environmental Kuznets curve'. Because the empirical evidence relies on reduced-form regressions of environmental quality on income and other covariates, most researchers avoid interpreting those results structurally, leaving open the question of why pollution follows this inverse-U pattern. Nonetheless, a number of people have appealed to this empirical relationship to argue that economic growth by itself is a panacea for environmental degradation. Beckerman (1992), for instance, writes that 'in the end the best — and probably the only way to attain a decent environment in most countries is to become rich', while Bartlett (1994) claims that 'existing environmental regulation, by reducing economic growth, may actually be reducing environmental quality'. It is important, therefore, to understand the nature and causes of the environmental Kuznets curve before adopting such far reaching, and to many quite alarming, implications for policy.

A number of plausible explanations exist for the observed inverse-U relationship. First, it could be that the pattern reflects the natural progression of economic development, from clean agrarian economies to polluting industrial economies to clean service economies (Arrow et al., 1995). This mechanism may be facilitated by advanced economies exporting their pollution-intensive production processes to less-developed countries (Suri and Chapman, 1998). If the downward-sloping portion of the pollution-income relationship is due to this type of pollution exporting, then the process of environmental improvement will not be indefinitely replicable, as the world's poorest countries will never have even poorer countries to which they can export their pollution.

An alternative explanation for the inverse- $U$ notes that pollution involves externalities, and that appropriately internalizing those externalities requires relatively advanced institutions for collective decision-making that may only be implementable in developed economies. Jones and Manuelli (1995), for example, posit an overlapping generations model in which economic growth is determined by market interactions and pollution regulations are set through collective decision-making by the younger generation. Depending on the decision-making institution, the pollution-income relationship can be an inverted-U, monotonically increasing, or even a 'sideways-mirrored-S'.

Still others have suggested that pollution stops increasing and begins decreasing with income because, with economic growth, some constraint becomes nonbinding. Stokey (1998), for example, describes a static model with a choice of production technologies with varying degrees of pollution. Her critical assumption is that below a threshold level of economic activity, only the dirtiest technology can be used. With economic growth, pollution increases linearly with income until the threshold is passed and cleaner technologies can be used. The resulting pollution-income path is therefore inverse-V-shaped, with a sharp peak at the point where a continuum of cleaner technologies becomes available. Similarly, Jaeger (1998) rests on the assumption that at low levels of pollution consumers' taste for 
clean air is satiated, and that the marginal benefit of additional environmental quality is zero. Like Stokey, therefore, Jaeger's pollution-income relationship is inverse-V-shaped, peaking when the optimum moves from a corner solution to an interior solution.

John and Pecchenino (1994) present an overlapping generations model in which environmental quality is a stock resource that degrades over time unless maintained by investment in the environment. An economy that begins at the corner solution of zero environmental investment will see its environmental quality decline with time and with economic growth until the point at which positive environmental investment is desired, when environmental quality will begin improving with economic growth. Like Stokey (1998) and Jaeger (1998) therefore, John and Pecchenino's pollution-income relationship exhibits an inverse-V shape, peaking when the dynamic equilibrium switches from a corner solution of zero environmental investment to an interior optimum with positive investment.

Other theoretical contributions to this literature include Selden and Song (1995), who describe a variety of possible pollution-income paths in a dynamic growth model, Chaudhuri and Pfaff (1998b), who posit a particular mechanism, bundled commodities, to explain the environmental Kuznets curve, and Kelly (1999), who focuses on the irreversible nature of many pollution problems as a driving force behind the curve. As Selden and Song (1995) themselves note, 'the complexity of those models can obscure the central forces involved'.

Each of these explanations yields a different policy implication. The pollutionexporting hypothesis of Suri and Chapman (1998) implies that international trade and capital controls may be necessary. The political-economic model of Jones and Manuelli (1995) suggests that developing countries, unable to enact efficient policies, could benefit from international assistance setting up effective environmental institutions. And the various dynamic models with multiple equilibria all imply that any government policy which speeds the transition from one equilibrium to another (i.e. encourages growth) would be beneficial for the environment.

By contrast to many of these prior explanations, this paper lays out a simple and straight-forward static model of the microfoundations of the pollution-income relationship. We show that the observed inverse- $U$ pattern does not require dynamics, predetermined patterns of economic growth, multiple equilibria, released constraints, political institutions, bundled commodities, irreversible pollution, or even externalities. Rather, an environmental Kuznets curve can be derived directly from the technological link between consumption of a desired good and abatement of its undesirable byproduct. Furthermore, it can be consistent with either a Pareto efficient policy or a decentralized market economy.

Moreover, in addition to simplifying prior explanations for the pollution-income relationship, our model encompasses many of those explanations. We will show that a key feature of our static, one-sector model is increasing returns to abating 
pollution. The more gross pollution there is before abatement, the less costly it is to abate one unit of that pollution. These scale economies generalize the specific features of many existing models. For example, Stokey's (1998) assumption that poor countries use only the dirtiest technologies could be justified by the existence of fixed costs (scale economies) in pollution abatement. Similarly, the fixed costs of establishing a capable environmental agency, described by Jones and Manuelli (1995), generate scale economies from a societal perspective. In sum, the model presented below generates many of the implications of existing models, without their specific assumptions. In this way, it highlights a common feature driving the inverse-U-shaped pollution-income path: increasing returns to abating pollution.

\section{A model of the pollution-income relationship}

We begin our model with the simplifying assumption of an economy with only one person. The one-person model is useful for two reasons. The first is its simplicity. More importantly, however, a one-person model can have no externalities, so any solution may be interpreted as Pareto efficient. We generalize our analysis to an economy with many individuals in Section 5 below.

Suppose the single agent gets utility from consumption of one private good, denoted $C$, and from a bad called pollution, $P$. Then preferences can be written:

$$
U=U(C, P)
$$

where $U_{C}>0$ and $U_{P}<0$, and $U$ is quasiconcave in $C$ and $-P$. Suppose further that pollution is a byproduct of consumption, and that our consumer has a means by which he can alleviate pollution by spending resources either to clean it up or, equivalently, to prevent it from happening at all. Call those resources $E$, for environmental effort. Pollution is then a positive function of consumption and a negative function of environmental effort:

$$
P=P(C, E)
$$

where $P_{C}>0$ and $P_{E}<0$. Finally, suppose that a limited endowment, $M$, of resources can be spent on $C$ and $E$. For simplicity, normalize the relative costs of $C$ and $E$ to be 1 . The resource constraint is therefore simply $C+E=M$.

Consider a simple example:

$$
\begin{aligned}
& U=C-z P \\
& P=C-C^{\alpha} E^{\beta}
\end{aligned}
$$

Utility in Eq. (3) is linear and additive in $C$ and $P$, and $z>0$ is the constant marginal disutility of pollution. Pollution in Eq. (4) has two components. The first, $C$, is gross pollution before abatement and is directly proportional to consumption. The second term of Eq. (4), $C^{\alpha} E^{\beta}$, represents 'abatement'. Eq. (4) indicates that 
consumption causes pollution one-for-one, but that resources spent on environmental effort abate that pollution with a standard concave production function. ${ }^{2}$

Begin with the case where $z=1$. Substituting Eq. (4) into Eq. (3) implies the individual is maximizing $C^{\alpha} E^{\beta}$ subject to $C+E=M$, hence consumption and effort have standard Cobb-Douglas solutions:

$$
C^{*}=\frac{\alpha}{\alpha+\beta} M \quad \text { and } \quad E^{*}=\frac{\beta}{\alpha+\beta} M
$$

Substituting Eq. (5) into Eq. (4), the optimal quantity of pollution is then:

$$
P^{*}(M)=\frac{\alpha}{\alpha+\beta} M-\left(\frac{\alpha}{\alpha+\beta}\right)^{\alpha}\left(\frac{\beta}{\alpha+\beta}\right)^{\beta} M^{\alpha+\beta}
$$

The derivative of Eq. (6) represents the slope of the environmental Kuznets curve:

$$
\frac{\partial P^{*}}{\partial M}=\frac{\alpha}{\alpha+\beta}-(\alpha+\beta)\left(\frac{\alpha}{\alpha+\beta}\right)^{\alpha}\left(\frac{\beta}{\alpha+\beta}\right)^{\beta} M^{\alpha+\beta-1}
$$

the sign of which depends on the parameters $\alpha$ and $\beta$.

When $\alpha+\beta=1$, effort spent abating pollution has constant returns to scale, and $\partial P^{*} / \partial M$ is constant. Given $0 \leq \alpha, \beta \leq 1$, then $P^{*}$ rises with $M$ and there is no downward sloping portion of the pollution-income curve, as depicted in Fig. 1A.

When $\alpha+\beta \neq 1$, the second derivative of Eq. (6) is:

$$
\frac{\partial^{2} P^{*}}{\partial M^{2}}=-(\alpha+\beta-1)(\alpha+\beta)\left(\frac{\alpha}{\alpha+\beta}\right)^{\alpha}\left(\frac{\beta}{\alpha+\beta}\right)^{\beta} M^{\alpha+\beta-2}
$$

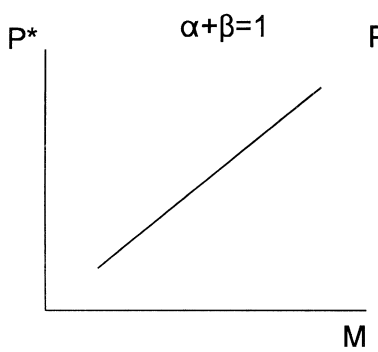

(A)

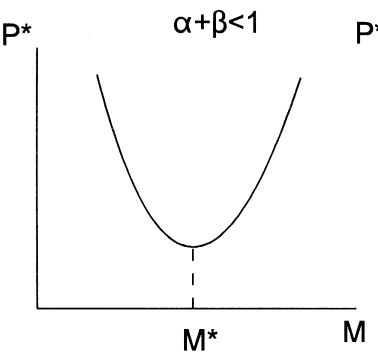

(B)

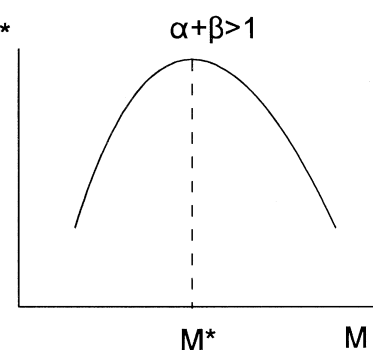

(C)

Fig. 1. Optimal pollution-income paths.

\footnotetext{
${ }^{2}$ Note that it is possible, in this framework, for $\partial P / \partial C<0$. However, Eq. (4) is a resource constraint, and in the optimum, the resource constraint will be tangent to an indifference curve with a positive slope in $(P, C)$ space. Therefore, it will never be optimal for the agent or a social planner to choose levels of consumption and pollution such that $\partial P / \partial C<0$.
} 
Thus, if $\alpha+\beta<1$, so that abatement exhibits diminishing returns to scale, $P^{*}(M)$ is convex, as in Fig. 1B. Likewise, if $\alpha+\beta>1$, so that abatement exhibits increasing returns to scale, then $P^{*}(M)$ is concave as in Fig. $1 \mathrm{C}^{3}$ This is what has been described as an environmental Kuznets curve.

When $z \neq 1$ the algebra becomes slightly more complex, but the optimal pollution-income curve remains inverse- $U$ shaped if and only if the abatement technology has increasing returns to scale: $\alpha+\beta>1$ in this example. Solving for the first-order condition and rearranging its terms yields:

$$
\begin{aligned}
C^{*} & =\frac{\alpha}{\alpha+\beta} M+\frac{1-z}{z(\alpha+\beta) C^{\alpha-1}(M-C)^{\beta-1}} \\
& =\frac{\alpha}{\alpha+\beta} M+B \frac{(1-z)}{z}
\end{aligned}
$$

where $B>0$. If $z<1$, our individual has lower marginal disutility from pollution, then $C^{*}$ is larger than in Eq. (5) and pollution $P^{*}$ is also correspondingly larger at every level of income. If $z>1$, representing a higher marginal disutility from pollution, $C^{*}$ and $P^{*}$ are smaller. Though the optimal levels of $C^{*}$ and $P^{*}$ at any income change in response to changes in $z$, the implications for the inverse-Ushaped pollution-income path remain the same.

So far, we have deliberately kept preferences simple in order to focus attention on the effects of technology. The inverse- $U$ does not depend on either consumption or lack-of-pollution being inferior goods, nor does it depend on tastes changing as income changes. Rather, it depends on the technological link between a good (consumption) and a bad (pollution). The critical link is that consumption of the good generates pollution, and that expenditure of resources on abatement ameliorates that pollution. High-income individuals demand more consumption and less pollution. When abatement is possible with increasing returns, highincome individuals can more easily achieve both goals.

\section{General sufficient conditions for an inverse-U-shaped pollution-income relationship}

Consider a general version of the model presented above:

$$
\begin{aligned}
U & =U(C, P) \\
P & =C-A(C, E) \\
& =C-A(C, M-C)
\end{aligned}
$$

\footnotetext{
${ }^{3}$ Note that the returns to scale are naturally bounded by the fact that pollution can only be abated to the extent it is generated in the first place, and that the more resources $(M)$ devoted to abatement effort $(E)$, the less there are available for pollution-generating consumption $(C)$.
} 
where $A()$ is the abatement production function, increasing in environmental effort $E$ and in existing pollution $C$. In this general case, we can define relatively weak sufficient conditions for the optimal pollution-income relationship to be inverse-Ushaped.

Theorem 1. Assume that the utility function $U(C, P)$ is quasiconcave in $C$ and $-P$, and that $C$ and $-P$ are both normal goods. Then if there exists a value $\theta$ such that:

$$
\lim _{C \rightarrow M} R(C) \equiv \frac{\partial U(C, 0) / \partial C}{\partial U(C, 0) / \partial P} \geq \theta>-\infty
$$

and a pollution abatement function $A(C, M-C)$ as in Eq. (10) that is concave and homogeneous of degree $k>1$, where $A(0, x)=A(x, 0)=0$ for all $x$, then for any combination of utility and abatement technology that yields positive pollution for some level of income, optimal pollution will eventually decline back to zero for some sufficiently large income.

First note that this statement amounts to a description of an environmental Kuznets curve. When resources are zero $(M=0)$, consumption and pollution are zero, by definition. The statement asserts that for some large $M$, optimal pollution will also be zero. For any parameterizition of utility and abatement technologies that lead to positive pollution for some level of income, the optimal pollution path must therefore increase from zero and then decrease back to zero, exactly the pattern observed empirically.

For an intuitive sketch of the proof, consider Fig. 2. ${ }^{5}$ Panel A depicts the consumption-environmental effort resource constraint, and an 'iso-abatement' curve indicating combinations of consumption $(C)$ and effort $(E)$ yielding the same amount of abatement. Since the abatement function $A(C, E)$ is homogeneous, we can depict the resource constraint in units of consumption and effort per unit of the resource, $C / M$ and $E / M$, respectively. By homogeneity of $A()$, the point of maximum abatement, where the highest iso-abatement curve is tangent to the resource constraint, will remain impervious to changes in income.

Panel B of Fig. 2 plots abatement per unit of the resource, $A / M$, peaking at the point of maximum abatement. The plot of $P / M$ is simply $C / M-A / M$, gross pollution less abatement, per unit of $M$. This line, $P / M$, represents the pollutionconsumption tradeoff in terms of the two goods in the utility function, $U(P, C)$. As

\footnotetext{
${ }^{4}$ Two caveats are in order here. First, note that this theorem does not require that the pollutionincome path be smoothly inverse-U-shaped, only that it increase and then decrease. The specific parameters in Section 2, by contrast, generate a smooth inverse-U-shaped path. Second, note that in practice we do not require that pollution actually reach zero, only that it tend in that direction. To facilitate the proof, however, we show that for some large $M$, perhaps impractically large, optimal pollution will be equal to zero.

${ }^{5}$ For a more formal proof, see Appendix A, or the working-paper version of this paper (Andreoni and Levinson, 1998).
} 
(A)

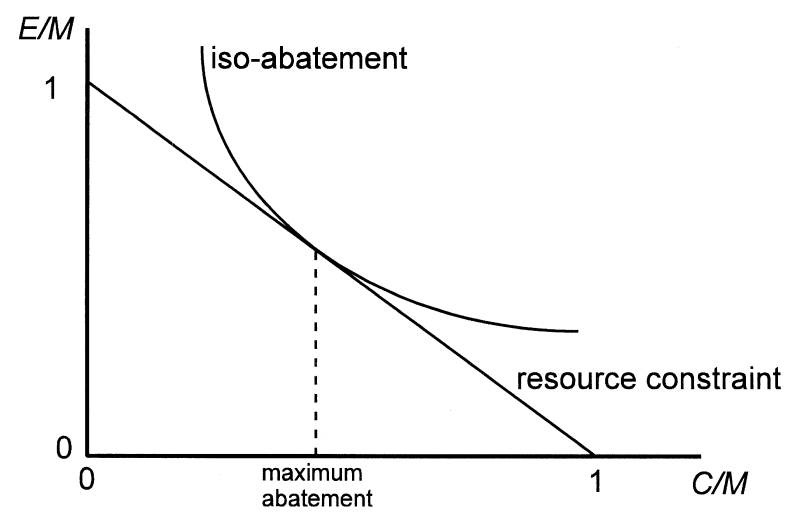

(B)

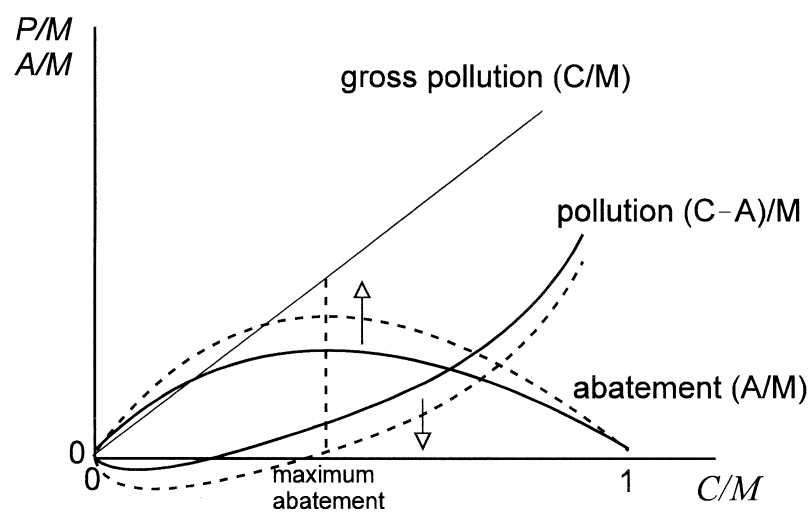

(C)

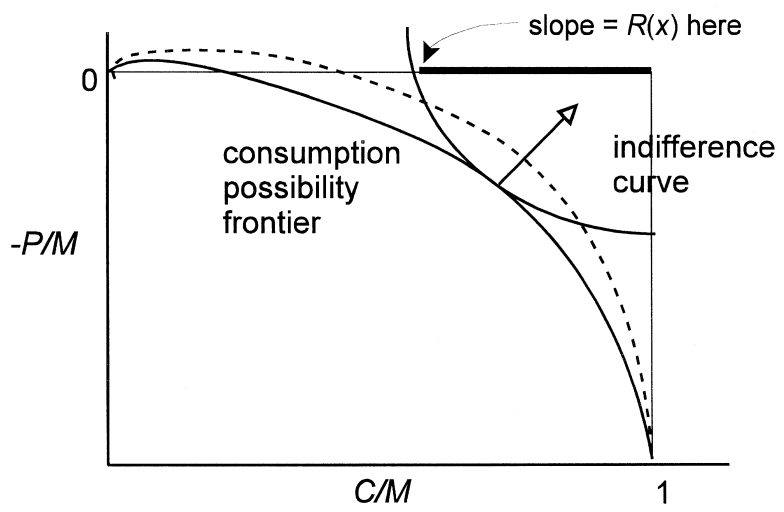

Fig. 2. A sketch of the proof of Theorem 1. 
$M$ increases, $P / M$ and $A / M$ change, depending on whether $A()$ is homogeneous of degree $k>1$ or $k<1$. If $k=1$, then doubling resources $(M)$ doubles effort $(E)$, consumption $(C)$, and abatement $(A)$, and the picture remains unchanged. If $k<1$, abatement has decreasing returns, then doubling $M$ will less than double abatement, more than double pollution, and $P / M$ will increase. If $k>1$, abatement has increasing returns, then doubling $M$ will more than double abatement, and $P / M$ will decrease, as depicted in Fig. 2B.

Panel $\mathrm{C}$ of Fig. 2 reverses the left axis of the graph in panel $\mathrm{B}$, so that $-P / M$ plotted against $C / M$ looks like a more familiar consumption possibility frontier. The optimum combination of pollution and consumption, per unit of resources, is depicted by the point of tangency between an indifference curve and this consumption frontier. ${ }^{6}$ If abatement has increasing returns $(k>1)$, as resources $(M)$ increase the consumption frontier shifts up and to the right, while remaining anchored at the corners where $P / M=0$ and $C / M=1$. With larger and larger values of $M$, the consumption frontier becomes steeper and steeper, asymptoting towards minus infinity. As long as the indifference curve itself does not become infinitely steep, the point of tangency between the consumption frontier and the indifference curve will move up and to the right, eventually crossing the thickly shaded line segment where $P=0$.

This last condition, that the indifference curve not be infinitely steep when $P=0$, is the assumption in Eq. (11). $R(C)$ is the marginal rate of substitution between consumption and pollution when $P=0$. Eq. (11) assumes that this slope does not go to minus infinity as $M$ increases indefinitely.

Evaluating the sufficient condition on preferences, we see that it is quite weak. Eq. (11) requires that the marginal willingness to pay for consumption in terms of pollution does not go to infinity. The converse of that is simply that the marginal willingness to pay to clean up the last speck of pollution does not go to zero as income goes to infinity. The standard notion that pollution clean-up is a normal good means that this assumption is natural and easily satisfied. The condition that

\footnotetext{
${ }^{6}$ Fig. 2C makes clear why no optimum will have the feature that $\partial P / \partial C<0$, a concern raised in footnote 2. Pollution decreases with consumption at the very left portion of the consumption possibilities frontier, where it is upward sloping, and where it can never be tangent to any indifference curve.

${ }^{7}$ We need not rule out values of $P^{*}<0$, negative pollution. The critical point is that $P^{*}$ tends towards $P^{*}=0$. Whether it ever gets there, gets stuck at a corner solution, or goes beyond to $P^{*}<0$ is irrelevant to establishing the existence of an environmental Kuznets curve. In fact, we could interpret 'zero pollution' as corresponding to some subjective original level of pollution and 'zero consumption' as the associated level of consumption (without any abatement). This original level of pollution could be interpreted as that in the poorest and cleanest economies. In this way, we do not have to imagine a world without human consumption, nor do we need to be troubled by the assumption that it is possible to have negative pollution. We can then interpret the model as saying it is possible to return to this original level of pollution.
} 
the abatement technology exhibits increasing returns to scale is also reasonable, and we address that issue next.

\section{Does pollution abatement exhibit increasing returns to scale?}

The lynchpin of the above analysis is that the abatement technology $A(C, E)$ exhibits increasing returns to scale. Do increasing returns make intuitive sense? Put differently, if we double both pollution and clean-up effort, will we get more than double the pollution abated? Begin by considering a simple example similar to that modeled in the previous section: the technology for sweeping a floor. The inputs to abatement are, first, a floor with a layer of dust one centimeter thick $(C)$ and, second, a person providing an hour of sweeping $(E)$. Now consider two centimeters of dust and two hours of sweeping over the same floor. If the person can sweep equally fast in both cases, then doubling these two inputs to abatement will clean up four times the dust, implying increasing returns to scale. As the dust gets thicker and heavier the sweeper may no longer be able to cover the same floor space in an hour, but his rate of sweeping would have to be cut in half before increasing returns switches over to decreasing returns.

Next consider some more realistic examples. Suppose the method of cleaning that has the cheapest marginal cost also requires the largest fixed cost, such as installing scrubbers on a smoke stack. A small economy may not be rich or polluted enough to get a good return on the fixed costs of the cleaning technology, and thus may rely on a technology with low fixed costs but high marginal costs. For larger economies, a greater share of manufacturing will be of sufficient scale that the low-marginal-cost/high-fixed-cost technology is cost-effective. Hence, for a larger economy the marginal cost of cleaning pollution may be beneath that of the smaller economy. If so, the abatement technology $A(C, E)$ will satisfy the sufficient condition of increasing returns to scale.

Engineering studies of abatement costs suggest that technologies for controlling some pollutants do exhibit increasing returns to scale of this type. The Environmental Protection Agency (EPA, 1978) studied the costs of controlling emissions from large coal-fired boilers. For sulfur dioxide emissions, they examined five different types of coal, five different emissions control technologies, and three levels of abatement. Each combination exhibited significant economies of scale. To reduce $90 \%$ of the sulfur dioxide from eastern (high-sulfur) coal with $3.5 \%$ sulfur content, costs ranged from 32 mills per kilowatt hour for a 25 megawatt boiler down to 8 mills/kWh for a 1000-MW boiler. ${ }^{8}$ Similarly, for particulate emissions, the EPA examined two types of coal, three control technologies and three abatement levels, all of which exhibited economies of scale.

\footnotetext{
${ }^{8}$ Expressed in 1980 dollars.
} 
To meet the most stringent particulate standard, burning high-sulfur coal and using an electrostatic precipitator, cost 4.6 mills/kWh for a $25-\mathrm{MW}$ boiler and 1.1 mills/kWh for a 1000-MW boiler. Emissions control cost studies of other pollutants and at different times conclude similarly (EPA, 1992, 1994).

These plant-level returns to scale in abating pollution can easily translate into country-level returns, in one of several ways. It may be that through cross-plant externalities such as technology spillovers or 'learning by doing', the more pollution abatement activity taking place in a country, the less expensive each unit of abatement becomes. Or, it may be that larger economies have larger plant sizes. Fig. 3A and B present evidence for this latter possibility. In Fig. 3A, the average size of countries' oil-fired electric power plants, measured in megawatts of electricity capacity, is plotted against their GDP per capita. Larger economies do have significantly larger plant sizes, and the elasticity of plant size with respect to economy size is approximately 0.64. Fig. 3B presents similar evidence for oil refineries, another universally pollution-intensive industry. Larger economies also have larger oil refineries, as measured by their capacity in barrels per calendar day, and the elasticity of refining capacity with respect to GDP per capita is approximately 0.40 .

As a final piece of support for there being returns to scale in abating pollution, we have examined data on abatement costs across US states and industries. Table 1 presents regressions of pollution abatement operating costs (PAOC), by US state and two-digit SIC code, on a quadratic in the size of the respective industry in each state, as measured by its contribution to gross state product (GSP), and other covariates. In column (2), for example, PAOC for each industry, state, and year, is regressed on a quadratic in the contribution of the relevant industry and state to GSP in that year. The quadratic term is negative and statistically significant, indicating that larger industries spend proportionally less on pollution abatement, across industries, states, and years. Fig. 3C presents a plot of column (2) of Table 1.

In column (3), we add a time trend and state fixed effects. The positive trend coefficient indicates that pollution abatement costs have been a growing fraction of GDP, and that the returns to scale implied by the negative quadratic coefficient on GDP is not driven by intertemporal or cross-state heterogeneity alone. This is important because in order for this to be a fair test of returns to scale in abating pollution, we would like for there to be similar environmental regulations across states. To the extent that state standard stringency has remained constant in relative terms, both over time and across industries, the fixed effects in column (3) will control for the effect of different state regulations on PAOC. Column (4) adds industry fixed effects, and the curve becomes even more concave, as can be seen in Fig. 3C. In other words, larger industries spend proportionally more on pollution abatement. Once we control for this, the scale economies are even more pronounced.

To be completely sure that the curvature in Fig. 3C is not a product of changing 


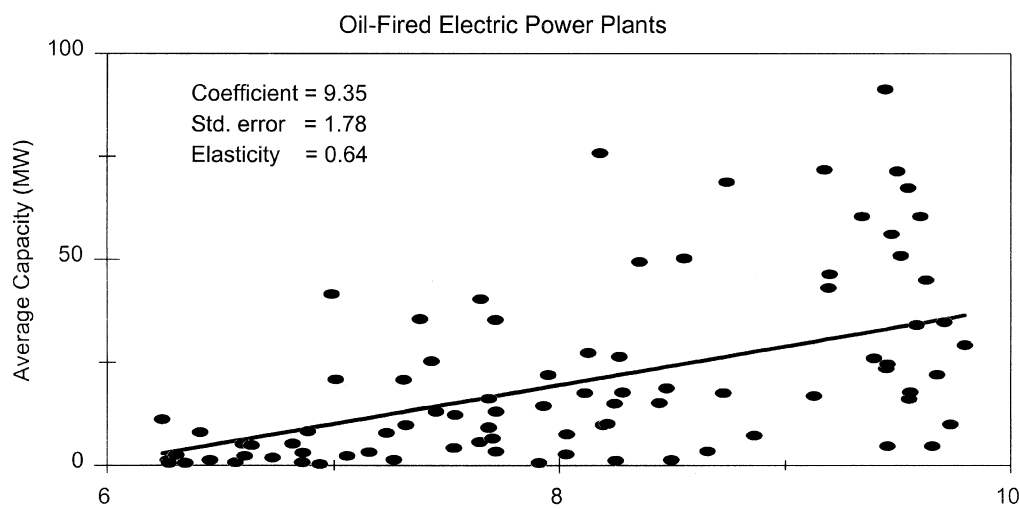

Source: Utility Data Institute,

Log 1992 GDP per capita, 88 countries World Electric Power Plant dataset.

(a)

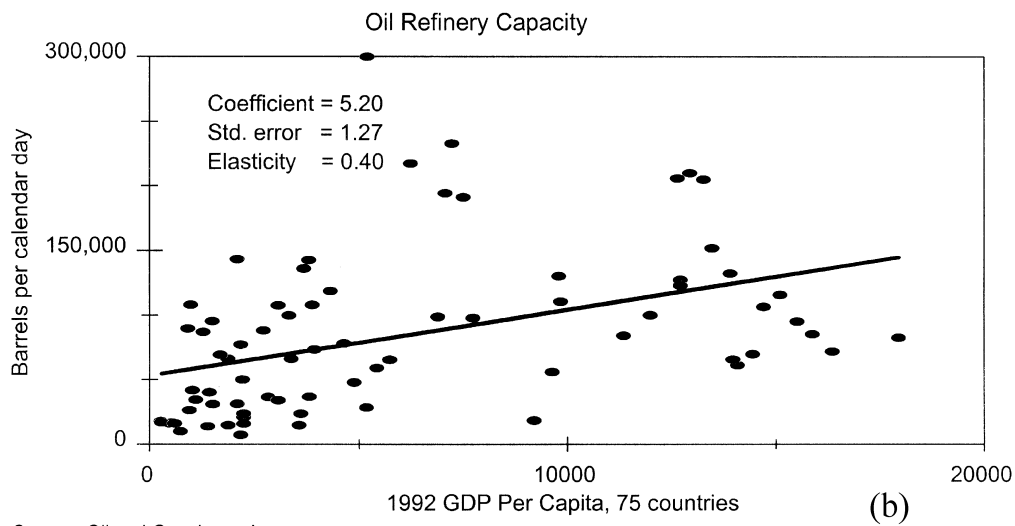

Source: Oil and Gas Journal

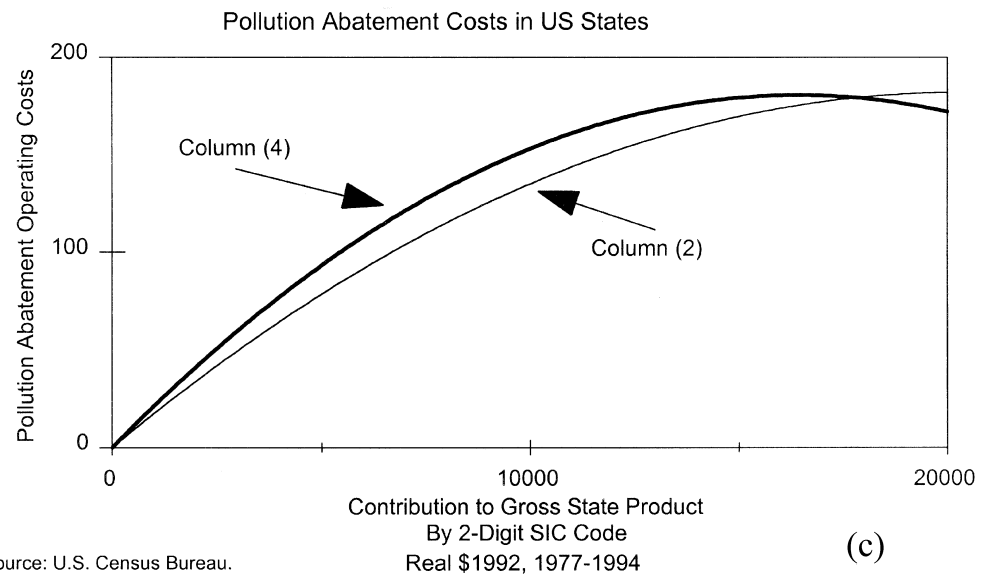

Fig. 3. Returns to scale in pollution abatement. 
Table 1

Quadratic OLS regressions of pollution abatement costs on gross state product: by state and two-digit SIC code $(1977-1994)^{\mathrm{a}}$

\begin{tabular}{|c|c|c|c|c|c|}
\hline $\begin{array}{l}\text { Dependent variable: } \\
\text { pollution abatement operating } \\
\text { costs ( } \$ 1992 \text { millions) }\end{array}$ & $\begin{array}{l}\text { Mean } \\
\text { (S.D.) } \\
\text { (1) }\end{array}$ & $\begin{array}{l}\text { GSP quadratic } \\
\text { only } \\
\text { (2) }\end{array}$ & $\begin{array}{l}\text { With time trend } \\
\text { and state } \\
\text { dummies } \\
\text { (3) }\end{array}$ & $\begin{array}{l}\text { Add industry } \\
\text { dummies } \\
\text { (4) }\end{array}$ & $\begin{array}{l}\text { Add relative } \\
\text { abatement cost } \\
\text { index } \\
\text { (5) }\end{array}$ \\
\hline $\begin{array}{l}\text { Gross state product (GSP) by } \\
\text { state and two-digit SIC } \\
\text { ( } \$ 1992 \text { millions) }\end{array}$ & $\begin{array}{l}1463 \\
(2065)\end{array}$ & $\begin{array}{c}0.0179 * \\
(0.0006)\end{array}$ & $\begin{array}{c}0.0175^{*} \\
(0.0006)\end{array}$ & $\begin{array}{c}0.0220^{*} \\
(0.0007)\end{array}$ & $\begin{array}{c}0.0221 * \\
(0.0007)\end{array}$ \\
\hline GSP $^{2}$ (billions) & & $\begin{array}{c}-0.00044 * \\
(0.00004)\end{array}$ & $\begin{array}{c}-0.00042 * \\
(0.00004)\end{array}$ & $\begin{array}{c}-0.00060^{*} \\
(0.00004)\end{array}$ & $\begin{array}{c}-0.00067^{*} \\
(0.00004)\end{array}$ \\
\hline Year & & & $\begin{array}{c}0.341 * \\
(0.117)\end{array}$ & $\begin{array}{c}0.269^{*} \\
(0.105)\end{array}$ & $\begin{array}{c}0.278^{*} \\
(0.105)\end{array}$ \\
\hline Abatement cost index & $\begin{array}{l}1.02 \\
(0.37)\end{array}$ & & & & $\begin{array}{c}8.34 * \\
(2.89)\end{array}$ \\
\hline Intercept & & $\begin{array}{c}0.413 \\
(0.913)\end{array}$ & & & \\
\hline State dummy variables & & No & Yes & Yes & Yes \\
\hline Industry dummy variables & & No & No & Yes & Yes \\
\hline$N$ & & 7147 & 7147 & 7147 & 7147 \\
\hline$R^{2}$ & & 0.23 & 0.28 & 0.46 & 0.46 \\
\hline
\end{tabular}

${ }^{\mathrm{a}}$ Standard errors in parentheses. * Significant statistically at 5\%. Each observation represents one particular two-digit SIC code, in one state, during one year. Missing are 1987, when the PAOC data were not collected, and 1979, when they were not published in a disaggregate format. Some state-industry combinations are censored by the Census Bureau to prevent disclosure of confidential information. PAOC data are based on US Census Bureau, 'Current Industrial Reports: Pollution Abatement Costs and Expenditures, MA-200', various years. Abatement cost index in column (5) is from Levinson (1999).

state regulations, in column (5) of Table 1 we add an index of relative state pollution costs, taken from Levinson (1999). The index measures the annual ratio of pollution abatement costs in each state to the national average, controlling for each state's industrial composition. Though the index's coefficient is positive and highly significant, its inclusion does not affect the measured scale economies of abatement costs.

In sum, we find evidence for returns to scale in abating pollution in many venues. At the plant level, larger industrial boilers cost less to control, per unit of abatement, than smaller boilers. At the national level, countries with larger economies have larger oil-fired electric power plants, and larger petroleum refineries, on average, than smaller economies. And at the level of US states, average pollution abatement costs per dollar of GSP decline with industry size, across states and industries, and over time. 
Before concluding, we return to one final key assumption of our model, that there is only one consumer.

\section{The case of many consumers}

By considering a model with a single consumer, we have ignored the fact that most environmental problems involve externalities. Indeed, one of the fundamental points made thus far is that externalities are unnecessary for the optimal pollutionincome relationship to be inverse-U-shaped. That said, the model can easily be generalized to incorporate externalities by increasing the population of consumers to $N>1$. To illustrate this, consider the following model:

$$
\begin{array}{ll}
U_{i}=C_{i}-P & i=1, \ldots, N \\
P=C-C^{\alpha} E^{\beta} & C=\sum_{i} C_{i}, \quad E=\sum_{i} E_{i} \\
M_{i}=C_{i}+E_{i} & \alpha, \beta \in(0,1)
\end{array}
$$

Individuals, indexed $i=1, \ldots, N$, are assumed to maximize utility as Nash players — they take others' consumption to be independent of their own. Solving the first order conditions yields the best response function:

$$
C_{i}^{*}=\frac{\alpha}{\alpha+\beta} M_{i}+\left[\frac{\alpha}{\alpha+\beta} \sum_{j \neq i} M_{j}-\sum_{j \neq i} C_{j}\right]
$$

If all individuals maximize utility in this manner, then the Nash equilibrium is:

$$
C_{i}^{*}=\frac{\alpha}{\alpha+\beta} M_{i} \text { for all } i
$$

In this decentralized case, pollution follows exactly the same path as in the one-person example in Eq.(6) - the pollution-income path is concave and peaked if and only if $\alpha+\beta>1$.

Notice that in the many-person example the solution is decentralized, and as a result is not Pareto efficient. To see this, assume a central planner maximizes the sum of utilities:

$$
\max \sum_{i} U_{i}=\sum_{i} C_{i}-N P
$$

This aggregate utility function is identical to Eq. (3), where $C$ is replaced by $\Sigma C_{i}$ and $z$ is replaced with $N$. Hence, all the solutions that follow will be identical, including the optimal consumption $C^{*}$ obtained in Eq. (9). Replacing $z$ with $N>1$, 
we see that in the decentralized solution Eq. (9), individuals consume too much and abate too little compared to the social optimum.

Increasing the number of consumers does not change the implications regarding the shape of the pollution-income path. That shape depends on the technology of abatement, not the number of polluters or the relative marginal utilities of consumption and environmental quality. Increasing $N$ merely lowers the optimal pollution-income path, as does increasing $z$, while retaining its inverse-U shape.

\section{Conclusions and further implications}

The model presented above, by its very simplicity, has several notable implications. First, it suggests that the observed income-environment relationship is perfectly reasonable. While some economists have created intricate politicaleconomy models of collective decision making, externalities and economic growth with inverse-U pollution patterns, our work suggests that those complications may be unnecessary to explain the observed patterns. Instead, the environmental Kuznets curve may result from simple and natural features of the abatement technology.

Second, the inverse-U-shaped pollution-income curve does not depend on externalities - it appears in both the single and many-person models. This is reassuring since several recent empirical studies find that household-level pollution also follows an inverse-U, consistent with our results (Chaudhuri and Pfaff, 1998a; Kahn, 1998).

Third, many of the existing explanations for the observed inverse- $U$ can be thought of as particular examples of increasing returns to scale in abatement, the principle driving the model presented here. For example, Stokey (1998) assumes that poor economies use only the dirtiest production technology, and only after passing an income threshold do they turn to cleaner methods. Such a process could be driven by fixed costs in abatement technologies, or increasing returns to scale in abatement. Alternatively, Jones and Manuelli (1995) model a world in which only advanced economies are sophisticated enough to establish political processes that correctly internalize externalities. One could think of those political processes being part of the societal abatement technology, and there being fixed costs, or increasing returns, to setting up environmental regulatory mechanisms. Increasing returns to scale in abatement thus broadly encompasses many of the existing models that derive inverse-U-shaped pollution-income paths.

Finally, the model does not support the argument that observed inverse-Ushaped pollution paths justify laissez-faire attitudes towards pollution, or that economic growth alone will solve pollution problems. Rather, we show that,

\footnotetext{
${ }^{9}$ As before, similar results hold for more general preferences.
} 
absent environmental regulations, the pollution-income path may well have an inverse-U shape, but the amount of pollution at every income will be inefficiently high. While it may be reasonable to deduce that at sufficiently high incomes the optimal pollution will be zero, the model in this paper places no limit on the level of income necessary to generate that return. Neither this paper, nor any of its empirical or theoretical predecessors, supports claims that environmental regulations are unnecessary.

What do these results indicate about future thinking on the environmental Kuznets curve? Foremost they suggest that simple explanations regarding the technology of production and abatement could be central to understanding the phenomenon. Second, they suggest that, based on the abatement technology, the pollution-income relationship can take on any shape, and we expect that for different pollutants, with different abatement technologies, the curves may or may not be inverse-U-shaped. Finally, our results underscore the plea in the introduction - we need to understand the structure and causes of the pollution-income relationship before incorporating that relationship into environmental policy.

\section{Acknowledgements}

The authors would like to thank Don Fullerton, Phil Haile, Alex Pfaff, and Tom Selden for helpful discussions of these issues, Jeff Hoerning for computer assistance, and the National Science Foundation for financial support.

\section{Appendix A. Proof of Theorem 1}

Define $L=-P$, as the 'lack' of pollution. Next, let $c=C / M$ and $\lambda \equiv L / M$. Then $\lambda(c)=A(c, 1-c) M^{k-1}-c$. For ease of notation, let $a(c)=A(c, 1-c)$. Since $A(c, 1-c)$ is assumed concave, $a(c)$ reaches a unique maximum for some $\bar{c}$. To make the model interesting, assume $0<\bar{c}<1$.

The consumption possibilities frontier in Fig. 2C is given by $\lambda(c ; M)=$ $a(c) M^{k-1}-c$. The slope of the frontier is $\partial L / \partial C=\partial \lambda / \partial c=\partial a / \partial c M^{k-1}-1$. For any $c>\bar{c}$, we can pick an $M$ such that $\lambda=L=0$. Call this level of income $\bar{M}(c)$, defined implicitly by $0 \equiv c-a(c) \bar{M}^{k-1}$, or $\bar{M}(c)=[c / a(c)]^{1 /(k-1)}$. So at $M=\bar{M}$, $l=0$ by definition, and when $M>\bar{M}$, the consumption possibility frontier in Fig. 2C shifts up, and $L \geq 0$ at the originally chosen level of $c$. Let $S$ be the slope of the consumption possibility frontier where it intersects $L=0$ for our given $c>\bar{c}$. Then:

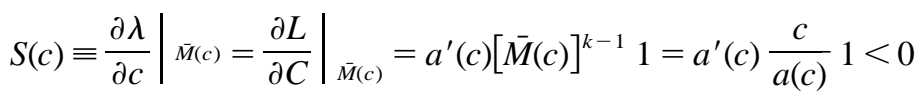


Because $\bar{c}$ is defined so that $a^{\prime}(c)<0$ for $c>\bar{c}$, the slope of this consumption possibility set, $S$, must be negative when $c>\bar{c}$.

Next, show what happens to this slope as $c$ increases. Differentiating Eq. (16) we see:

$$
\frac{\partial S}{\partial c}=a^{\prime \prime}(c) \frac{c}{a}+a^{\prime}(c)\left[\frac{a(c)-a^{\prime}(c) \cdot c}{(a(c))^{2}}\right]<0
$$

By concavity of $a(c)$, and the fact that $c>\bar{c}, \partial S / \partial c<0$. Then as $c$ goes to 1 , we know $a(c)$ goes to 0 . Hence, for finite $a^{\prime}, a^{\prime \prime}$ :

$$
\lim _{c \rightarrow 1} \frac{\partial S}{\partial c}=-\infty
$$

As we increase $c$ from $\bar{c}$ to 1 , in each case choosing a corresponding $\bar{M}(c)$ such that $\lambda=L=0$, along the thickly shaded line segment in Fig. $2 \mathrm{C}$, the slope of the consumption possibility constraint at $(c, \lambda)=(1,0)$ becomes arbitrarily steep.

Turning to the preferences side of the problem, first define $V(c, \lambda ; M) \equiv U(c M$, $-\lambda M)$, a representation of utility in $(c, \lambda)$ space, holding income constant, as in Fig. 2C. Then define:

$$
R(c) \equiv-\frac{\partial V(c, 0) / \partial c}{\partial V(c, 0) / \partial \lambda}
$$

as the marginal rate of substitution evaluated along the thick line segment in Fig. $2 \mathrm{C}$.

Normality of $C$ and $-P$ ensures that $\mathrm{d} R / \mathrm{d} c \leq 0$. The only way we would not have the indifference curve cross the consumption possibilities frontier as $M$ goes to infinity is if the MRS has an asymptote of minus infinity, just as the slope of the frontier does. Hence, we have now demonstrated the theorem - as long as $\lim _{c \rightarrow 1} R(c)$ is finite, which is true so long as Eq. (11) holds, then pollution must eventually return towards zero as income increases.

\section{References}

Andreoni, J., Levinson, A., 1998. The Simple Analytics of the Environmental Kuznets Curve. NBER, Working paper \#6739.

Arrow, K., Bolin, B., Costanza, R., Dasgupta, P., Folke, C., Holling, C., Jansson, B.O., Levin, S., Maler, K.G., Perrings, C., Pimentel, D., 1995. Economic growth, carrying capacity, and the environment. Science 268, 520-521.

Bartlett, B., 1994. The high cost of turning green. The Wall Street Journal. September 14.

Beckerman, W., 1992. Economic growth and the environment: Whose growth? Whose environment? World Development 20, 481-496.

Chaudhuri, S., Pfaff, A., 1998a. Household income, fuel choice, and indoor air quality: microfoundations of an environmental Kuznets curve. Economics Department, Columbia University, Working paper. 
Chaudhuri, S., Pfaff, A., 1998b. Household production, the bundling of services and degradation, and non-monotonic environmental Engle curves. Economics Department, Columbia University, Working paper.

EPA, 1978. Particulate and sulfur dioxide emission control costs for large coal-fired boilers. Environmental Protection Agency, EPA-450/3-78-007.

EPA, 1992. In: Control techniques for particulate emissions from stationary sources, Vol. 1. Environmental Protection Agency, EPA-450/3-81-005a.

EPA, 1994. Alternative control technologies document $\mathrm{NO}_{x}$ emissions from utility boilers. Environmental Protection Agency, EPA-453/R-94-023.

Galeotti, M., Lanza, A., 1999. Desperately seeking (environmental) Kuznets. International Energy Agency, Paris, Working paper.

Grossman, G., Krueger, A., 1995. Economic growth and the environment. Quarterly Journal of Economics 110 (2), 353-377.

Hilton, F.G.H., Levinson, A., 1998. Factoring the environmental Kuznets curve: evidence from automotive lead emissions. Journal of Environmental Economics and Management 35, 126-141.

Holtz-Eakin, D., Selden, T., 1995. Stoking the fires? $\mathrm{CO}_{2}$ emissions and economic growth. Journal of Public Economics 57 (1), 85-101.

Jaeger, W., 1998. A theoretical basis for the environmental inverted-U curve and implications for international trade. Williams College, Working paper.

John, A., Pecchenino, R., 1994. An overlapping generations model of growth and the environment. The Economic Journal 104, 1393-1410.

Jones, L.E., Manuelli, R.E., 1995. A positive model of growth and pollution controls. NBER, Working paper \#5205.

Kahn, M.E., 1998. A household level environmental Kuznets curve. Economics Letters 59 (2), 269-273.

Kelly, D., 1999. On Kuznets curves arising from stock externalities. University of Miami, Working paper.

Kuznets, S., 1955. Economic growth and income inequality. American Economic Review 45 (1), 1-28.

Levinson, A., 1999. An industry-adjusted index of state environmental compliance costs. NBER, Working paper \#7297.

Millimet, D.L., Stengos, T., 1999. A semiparametric approach to modeling the environmental Kuznets curve across US states. Southern Methodist University, Working paper.

Selden, T.M., Song, D., 1994. Environmental quality and development: Is there a Kuznets curve for air pollution emissions? Journal of Environmental Economics and Management 27, 147-162.

Selden, T.M., Song, D., 1995. Neoclassical growth, the J curve for abatement, and the inverted U curve for pollution. Journal of Environmental Economics and Management 29 (2), 162-168.

Shafik, N., Bandyopadhyay, S., 1992. Economic growth and environmental quality: Time series and cross-section evidence. World Bank, Policy research working paper \#WPS904.

Stokey, N.L., 1998. Are there limits to growth? International Economic Review 39 (1), 1-31.

Suri, V., Chapman, D., 1998. Economic growth, trade and energy: implications for the environmental Kuznets curve. Ecological Economics 25 (2), 195-208.

World Bank, 1992. World Development Report 1992. Oxford University Press, New York. 